\title{
Coal dense medium separation dynamic and steady-state modelling for process control
}

\author{
E.J. Meyer ${ }^{\mathrm{a}, \mathrm{b}}$, I.K. Craig ${ }^{\mathrm{b}, *}$ \\ ${ }^{a}$ Snr Solution Architect, MES E Plant - Business Solution Provision, Exxaro Resources, PO Box 9229, Pretoria 0001, South Africa \\ ${ }^{b}$ Department of Electrical, Electronic and Computer Engineering, University of Pretoria, Pretoria 0002, South Africa
}

\begin{abstract}
Coal dense medium separation is a popular beneficiation process used for the upgrading of coal ore into power station and metallurgical coal. The control systems used in coal beneficiation are often limited to localised regulatory control of feed rate and medium density. A coal dense medium separation process can benefit substantially from process control provided that a dynamic model for this process is available as was previously developed by the authors for a fine coal dense medium cyclone (DMC) circuit. In this paper, the previous model is adapted to a coarse coal DMC circuit and validated over a wider range of operating conditions using real plant data. The model is further validated by reducing it to steady-state to form a partition curve. This curve is then compared to one derived from actual production data. The derived model is able to provide an estimate of the DMC overflow coal product that should be sufficient for process control.
\end{abstract}

Keywords: dense medium separation, coal beneficiation, dynamic modelling, steady-state modelling, process control, simulation

\section{Introduction}

A coal dense medium separation (DMS) plant makes use of the principle of density separation to upgrade mined coal and produce metallurgical coal or power station coal. The objective of the DMS plant operation is to produce coal product within a minimum quality specification and maximum possible yield (England et al., 2002). Meyer and Craig (2010) have indicated that coal DMS plants do not typically operate at steady state and that setpoint changes should be tracked appropriately in terms of ash content and yield. Almost all DMS plants are only automatically controlled at the regulatory control level in terms of medium density and ore feed rate and there are significant financial implications if the average yield and ash content of product coal can be controlled and optimised.

Dynamic process models for the coal DMS process are limited in the available published literature (Meyer and Craig, 2010). Steady-state models developed by Napier-Munn (1991) cannot be used for process control purposes due to the need for time-varying process variables. DMS process models developed by Lyman et al. (1982) and Lyman et al. (1983) show dynamic process simulations which only focus on the regulatory control aspects such as medium density. A linear relationship between medium density and product coal ash content is assumed. This linear relationship results in the model only working within a narrow medium density band and can be viewed as a limitation. The dynamic models developed by Meyer and Craig (2010) are detailed in such a way that they can be used to simulate time-varying coal product quality and throughput. These models are based on first principles using conservation of mass and mass of components (Stephanopoulos, 1984) and can be used for simulating and validating process control strategies for DMS circuits. The models developed in Meyer and Craig (2010) were validated by comparing their responses to experimental data obtained from a fine coal dense medium cyclone (DMC) circuit. These data were generated from step changes in medium density, and the resulting changes in product ash content were carefully observed.

\footnotetext{
${ }^{*}$ Corresponding author. Tel.: +27 124202172 ; fax: +27 123625000

Email address: ian.craig@up.ac.za (I.K. Craig)
} 
This paper will focus on using the dynamic process models develop by Meyer and Craig (2010) for a fine coal DMC and identify and validate them using throughput and yield for a coarse DMC circuit. System identification (Ljung, 1987) is used to identify the developed models. Validation of the models are conducted with varying low pass filter cut-off frequencies to illustrate how the model fit varies by removing signal noise. The beneficiation process is similar to the fine circuit described in Meyer and Craig (2010), although the coarse cyclone equipment and operating conditions are different, with the yield being much higher than that of the fine cyclone.

Two experiments are performed to verify the models developed in this paper. Experiment one used a step change in throughput while medium density was kept constant. The second experiment used a step change in medium density while throughput was kept constant. These steps were found by searching historical production data for large input changes such that the derived models can be validated over a wide range of operating conditions. These input signals could possibly be made to better excite the dynamics in the process provided that the opportunity exists to manipulate the plant inputs in order to generate more sufficiently exciting input signals (Ljung, 1987).

The relationship between yield and ash through the washability characteristics of the coal (England et al., 2002) can be used to evaluate the quality of the coal product. Figure 1 illustrates the typical inverse relationship between throughput and quality (Bauer and Craig, 2008). Using coal washability, a similar inverse relationship would occur between coal throughput and yield.

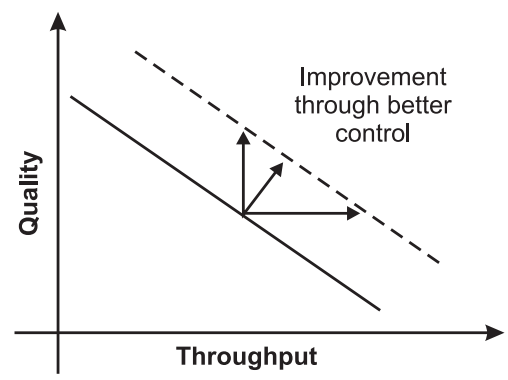

Figure 1: General throughput versus quality relationship with improvement through better control (Bauer and Craig, 2008).

Additional validation for the dynamic models of Meyer and Craig (2010) are presented in Meyer and Craig (2011), where the DMC model was reduced to a steady-state model which represents a DMC partition curve. This paper will further validate the DMC model by reducing the dynamic model developed from each experiment described above into a steady-state partition curve.

With the dynamic DMS process models being identified and validated with a larger input-output data set, these models are now more suitable for process control than the models described in Meyer and Craig (2010, 2011). Bauer and Craig (2008) show that the process control method of choice is model predictive control (MPC) (Camacho and Bordons, 2004). The MPC makes use of a dynamic model to predict future outputs based on past inputs and outputs. Using a reference setpoint, calculated future errors are used by an optimiser with a cost function and process constraints to determine future process inputs.

Section 2 describes the DMS process and associated measurement assumptions that are used for dynamic modelling. A brief description of the model identification and steady-state reduction is given in section 3 . An explanation of the two experiments that were conducted is also given in this section. Simulation results from the two experiments are given in section 4 . The steady-state partition curve validation is also detailed in this section.

\section{Process flow and measurements of the DMS process}

The DMS process used by Meyer and Craig (2010) is for a fine cyclone circuit whereas the circuit analysed in this paper is of a coarse cyclone circuit. Various assumptions had to be made in order to perform the system identification for the new equipment parameters. These assumptions are detailed below.

The process flow diagram in Figure 2 illustrates a two module DMS plant. The run-of-mine (ROM) coal ore is collected in a silo and fed to two different DMC modules through automatic feeders which can be controlled using a variable speed drive. The ROM coal is conveyed to a double deck screen where the oversize $(+25 \mathrm{~mm})$ is beneficiated 
using a drum separator. The feed rate of the silo feed conveyor is measured and controlled using the automatic feeder. The middle-sized $(-25+6 \mathrm{~mm})$ ROM coal is fed into a mixing box which is mixed with magnetite medium and pumped into the coarse cyclone circuit. The coarse cyclone overflow and underflow material is washed with a drain-and-rinse screen. The drain-and-rinse screen is physically divided (using a barrier) into two streams to ensure the coal product and discard are not mixed. The drain-and-rinse screen is sized such that the medium is washed off the coal (overflow) and discard (underflow) and collected in a medium recovery circuit. The medium is ultimately circulated back into the mixing box. The medium is density controlled through the addition of water.

The undersize $(-6 \mathrm{~mm}) \mathrm{ROM}$ coal from the primary screen is processed further in the fine cyclone circuit. The detail of this process can be found in Meyer and Craig (2010). It must be noted that all of the sized product from each module is combined and screened. The final product from the coarse section is therefore combined for each module. The feed rate of the combined coarse material is measured. Similarly, all discarded material is combined and the reject mass flow rate is measured. As a result, certain assumptions have to be made to determine the individual module mass flow rates for the coarse product and discard material.

The control and instrument names used to describe the measurements in Figure 2 are indicated in Table 1.

\begin{tabular}{ll}
\multicolumn{1}{c}{ Table 1: Instrument and control names for the DMS plant } \\
\hline Name & Description \\
\hline LIT1001 & Module one and two ROM silo level $(\%)$ \\
SC1002 & Module one automatic feeder variable speed controller $(\mathrm{Hz})$ \\
WIT1002 & Module one plant feed belt scale $(\mathrm{kg} / \mathrm{s})$ \\
WIC1002 & Module one plant feed rate controller $(\mathrm{kg} / \mathrm{s})$ \\
WIT2002 & Module two plant feed belt scale $(\mathrm{kg} / \mathrm{s})$ \\
WIT0300 & Module one drum plant feed belt scale $(\mathrm{kg} / \mathrm{s})$ \\
PIT1109 & Module one coarse cyclone inlet pressure $(\mathrm{Pa})$ \\
DIT1106 & Module one coarse cyclone circulating medium density $\left(\mathrm{kg} / \mathrm{m}^{3}\right)$ \\
DIC1106 & Module one coarse cyclone circulating medium density controller $\left(\mathrm{kg} / \mathrm{m}^{3}\right)$ \\
WIT3100 & Coarse product belt scale $(\mathrm{kg} / \mathrm{s})$ \\
WIT0305B & DMS plant discard belt scale $(\mathrm{kg} / \mathrm{s})$ \\
\hline
\end{tabular}

The following calculations indicated in Figure 2 are described in Table 2.

Table 2: Calculation assumptions for the DMS plant

\begin{tabular}{ll}
\hline Name & Description \\
\hline $\mathrm{C} 01$ & Module one calculated combined coarse and fine material feed rate $(\mathrm{kg} / \mathrm{s})$ \\
$\mathrm{C} 02$ & Module one calculated mixing box material feed rate $(\mathrm{kg} / \mathrm{s})$ \\
\hline
\end{tabular}

The assumptions made to determine the calculated measurement points are as follows:

- The coarse material feed rate of module one is a composition of the coarse product and discard material weighted by the ratio of the feed of module one to the total plant feed. The discard material for the coarse feed is weighted according to the yield of the total coarse material.

- The combined coarse and fine material feed rate for module one is calculated as the difference between the primary screen feed and the oversize feed.

- The density of the module one coarse cyclone feed is proportional to the measured cyclone inlet pressure.

- The feed rate of coarse product for module one is weighted according to the total plant feed.

- The feed rate of coarse discard for module one is weighted according to the ratio of module one's feed to the total plant feed and the yield of the total coarse material. 


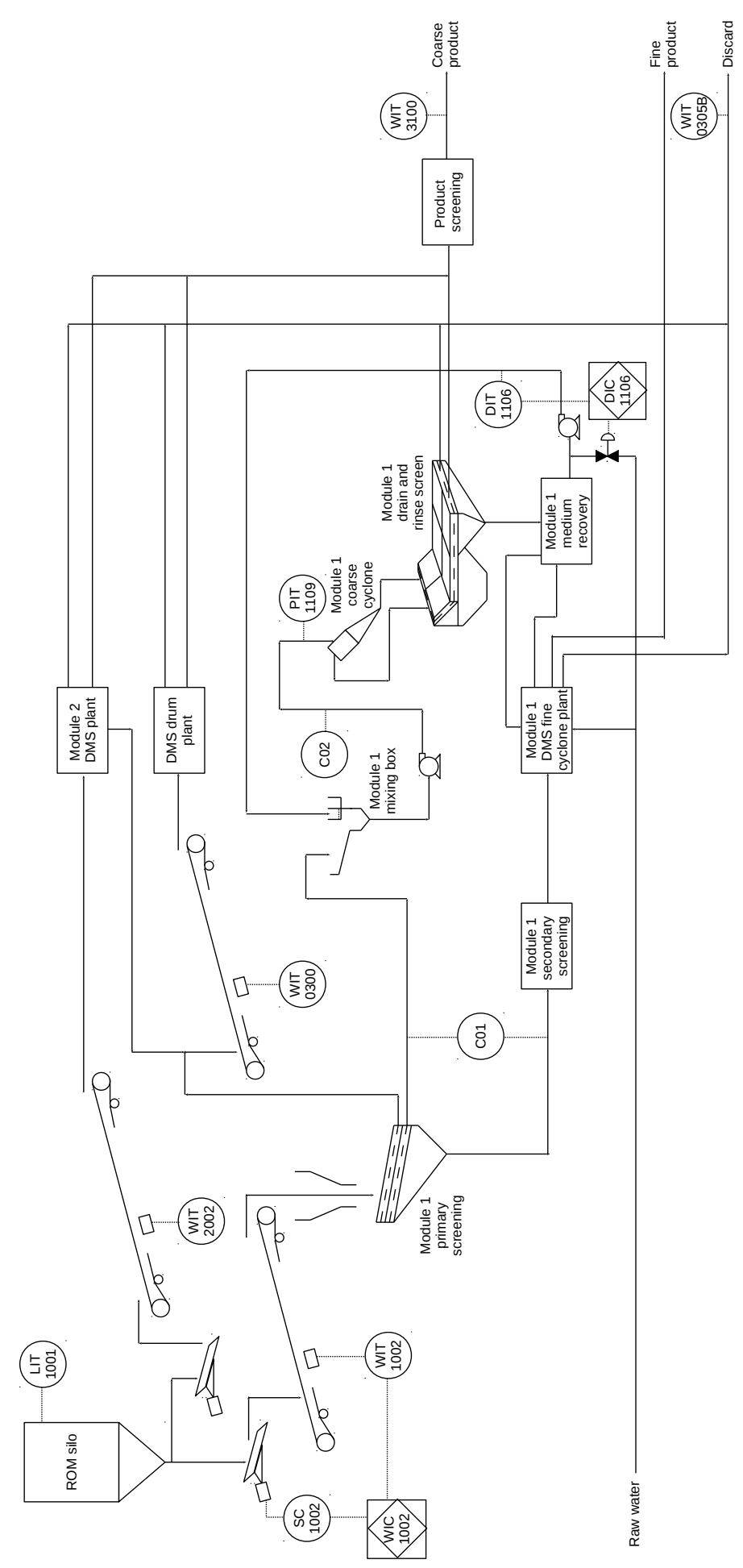

Figure 2: DMS plant process flow and instrumentation diagram indicating details of the coarse plant module 1 section. 
- All calculations can be time-delay adjusted to ensure a single reference point in time for all measured variables. This can be accomplished by adjusting the measured output using either negative or positive time delays where applicable.

The calculated combined coarse and fine material feed rate $\mathrm{C} 01(\mathrm{~kg} / \mathrm{s})$ is given as,

$$
\operatorname{C} 01(t)=\operatorname{WIT} 1002\left(t-\tau_{\mathrm{C} 01, i}\right)-\left(\frac{\mathrm{WIT} 1002\left(t-\tau_{\mathrm{C} 01, i}\right)}{\operatorname{WIT} 1002\left(t-\tau_{\mathrm{C} 01, i}\right)+\mathrm{WIT} 2002\left(t-\tau_{\mathrm{C} 01, i}\right)}\right) \operatorname{WIT} 0300(t) .
$$

The time delay $\tau_{\mathrm{C} 01, i}$ is used to delay the feed ore [WIT1002(t) and WIT2002(t)] such that their measurements are synchronised with the measurements of the primary screen.

Mukherjee et al. (2003) have indicated that a gravity fed DMC can typically have a head height of between 9 and 11 times the cyclone diameter $d$. The relationship between relative density, pressure and head height is,

$$
P=\rho g h,
$$

where $P$ is the cyclone inlet pressure $(\mathrm{Pa}), \rho$ is the inlet relative density $\left(\mathrm{kg} / \mathrm{m}^{3}\right), g$ is the gravitational constant $\left(9.81 \mathrm{~m} / \mathrm{s}^{2}\right)$ and $h$ is the head height of the feed $(\mathrm{m})$ which can be used to determine the DMC inlet density. Using the mixing box model from Meyer and Craig (2010), $h$ can be estimated as $9 D$ for the coarse cyclone, assuming a cyclone diameter $D$ of $0.8 \mathrm{~m} . \mathrm{C} 02(\mathrm{~kg} / \mathrm{s})$ can therefore be calculated from,

$$
\mathrm{C} 02(t)=\frac{Q_{m b} \operatorname{PIT} 1109(t)}{g h},
$$

where $Q_{m b}$ is the flow rate $\left(\mathrm{m}^{3} / \mathrm{s}\right)$ of the cyclone feed with associated cyclone pressure PIT1109( $\left.t\right)(\mathrm{Pa})$. Equation 3 is a new calculation introduced to the dynamic models developed in Meyer and Craig (2010) to provide and additional calculated measurement point for the process.

Each measurement point is adjusted in time by cross correlating it with the known measured value WIT0300 which acts as a reference point. The coarse coal product mass flow rate [WIT3100(t)] and DMS plant discard mass flow rate $[\mathrm{WIT} 0305 \mathrm{~B}(t)]$ are adjusted with negative time delays $\left(\tau_{\mathrm{WIT} 3100, d}\right.$ and $\left.\tau_{\mathrm{WIT} 0305 \mathrm{~B}, d}\right)$. The negative time delays are required to ensure the measurement data is synchronised with the DMC measurements. The following time delays

\begin{tabular}{|c|c|c|}
\hline Name & Value & Description \\
\hline$\tau_{\mathrm{C} 01, i}$ & $60 \mathrm{~s}$ & $\begin{array}{l}\text { Time delay between the measured plant feed and primary } \\
\text { screen }\end{array}$ \\
\hline$\tau_{\text {WIT3100, } d}$ & $-338 \mathrm{~s}$ & $\begin{array}{l}\text { Negative time delay required to shift the measured coarse } \\
\text { product time data back in time to match the cyclone } \\
\text { product overflow }\end{array}$ \\
\hline$\tau_{\text {WIT0305B }, d}$ & $-198 \mathrm{~s}$ & $\begin{array}{l}\text { Negative time delay required to shift the measured } \\
\text { discard time data back in time to match the cyclone } \\
\text { product underflow }\end{array}$ \\
\hline
\end{tabular}
were determined using cross correlations and are detailed in Table 3.

Table 3: Time delay estimates

$\tau_{\mathrm{C} 01, i}$ is the time delay used in equation 1 to delay the feed ROM such that it aligns with the oversize mass rate. $\tau_{\text {WIT3100,d }}$ and $\tau_{\text {WIT0305B, } d}$ are the time delays used to bring the coarse and discard mass flow rates back in time with the simulated output for validation purposes.

\section{Model validation and theory}

\subsection{System identification}

Ljung (1987) describes the system identification process where a dynamic model of a system can be fitted to a given set of data describing that system. Figure 3 illustrates this process of parameter estimation used by Meyer (2010). 


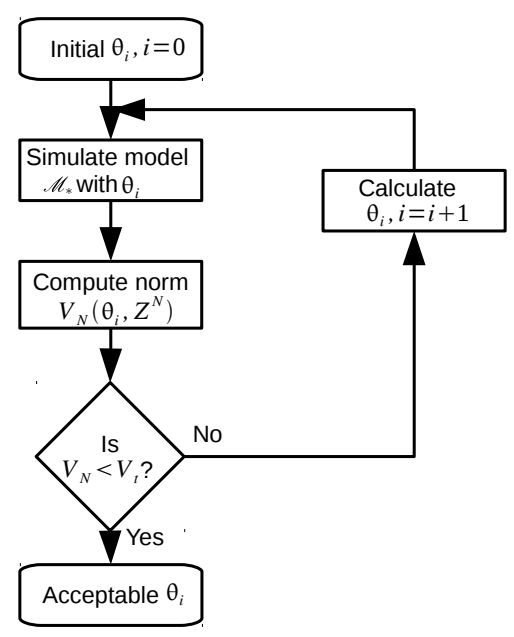

Figure 3: Parameter estimation process (Rathaba, 2004). $\mathscr{M}_{*}$ refers to the different equipment models.

Meyer (2010) shows how the system identification process was used to determine the parameters for a screen, mixing box and DMC dynamic model $\left(\mathscr{M}_{*}\right)$. In this process the prediction error $(\epsilon)$ represents the difference between the measured and the model output for a given set of model parameters. The process of selecting the model parameters that minimise the prediction error is called parameter estimation (Ljung, 1987). The scalar-valued norm approach is used in this paper where the norm of the normalised sum of the square of the prediction errors (loss function) is minimised. The loss function is given as,

$$
V_{N}=\operatorname{det}\left(\frac{1}{N} \sum_{1}^{N} \epsilon\left(t, \theta_{i}\right)\left(\epsilon\left(t, \theta_{i}\right)\right)^{T}\right)
$$

where $\theta_{i}$ represents the $i$ th estimated parameter and $N$ is the number of values in the estimation data set $\left(Z^{N}\right)$. When the loss function is below a threshold $\left(V_{t}\right)$, the algorithm stops and returns the parameter set $\left(\theta_{i}\right)$ which fits the model and data set within the required threshold.

The prediction-error identification algorithm that was used is the Trust-Region Reflective Newton numerical optimisation algorithm (Ljung, 2005) for estimating non-linear grey-box models. The quality of each model ( $\left.\mathscr{M}_{*}\right)$ estimate is measured using Akaike's final prediction error (FPE) (Ljung, 2010),

$$
\mathrm{FPE}=V_{N}(1+2 d / N),
$$

where $V_{N}$ is the loss function and $d$ is the number of estimated parameters.

The parameters have been identified using $66 \%$ of the data from each experiment. The model parameter fit was determined by minimising the loss function over $66 \%$ of the data set, while the model goodness of the fit was determined for the full data set for each experiment. Model goodness of the fit (Ljung, 2005) is determined using the normalised root mean square error,

$$
\text { fit }=100\left(1-\frac{|y-\hat{y}|}{|y-\bar{y}|}\right)
$$

where $y$ is the measured output, $\hat{y}$ is the simulated output and $\bar{y}$ is the mean of $y\left(\sum_{i=1}^{N} y_{i} / N\right)$. The normalised root mean square error $(|y-\hat{y}|)$ is determined as $\sqrt{\sum_{i=1}^{N}\left(y_{i}-\hat{y}_{i}\right)^{2}} / N$. Similarly, $|y-\bar{y}|$ is evaluated as $\sqrt{\sum_{i=1}^{N}\left(y_{i}-\bar{y}\right)^{2}} / N$.

The model parameters for the various equipment is similar to that described in Meyer and Craig (2010), but are adapted here to a coarse DMS process. The first model is a combination of the screen model and mixing box model. For the first model, parameters were determined for the time it takes for material to travel over each top deck screen component $\left(\tau_{o}\right)$, through the top deck screen component $\left(\tau_{c, o}\right)$, over the bottom deck screen component $\left(\tau_{c}\right)$ and through the bottom deck screen component $\left(\tau_{f, c}\right)$. The percentage of mass split for the top and bottom deck was 
determined from the particle size distribution of the feed as described in Meyer and Craig (2010). The parameter for the mixing box is the volume required for perfect mixing $\left(V_{m b}\right)$.

For the second model, the DMC model was only identified using the throughput and medium and no quality mass components such as ash percentage, the overflow and underflow proportionality constant $(\alpha)$ and proportionality constants for the overflow $\left(K_{c, o}\right)$, underflow $\left(K_{c, u}\right)$, medium overflow $\left(K_{c, o, \text { med }}\right)$, medium underflow $\left(K_{c, u, m e d}\right)$ and cyclone volume $\left(V_{c}\right)$ were determined. An ash feed percentage of $18.8 \%$ and carbon content of $53.4 \%$ were assumed. The ash feed percentage and carbon content assumption is based on official four hourly laboratory results obtained from a composite sample during the time of plant operation. A cyclone volumetric throughput rate of $0.07 \mathrm{~m}^{3} / \mathrm{s}$, medium-to-ore volumetric ratio of $5: 1$ and medium density overflow and underflow to feed difference of $50 \mathrm{~kg} / \mathrm{m}^{3}$ were used. The cyclone volumetric throughput assumption is based on the physical cyclone geometry while the medium-to-ore volumetric ratio and medium density difference are typical values taken from literature (Gupta and Yan, 2006; He and Laskowski, 1994).

Table 4 indicates the values that were estimated using the data from experiments one and two. The resulting simulation results are given in section 4 .

\begin{tabular}{lll}
\multicolumn{2}{c}{ Table 4: Model parameters determined from experiments one and two. } \\
\hline Equipment model & Parameter & Estimate \\
\hline \hline \multirow{2}{*}{ Double-deck } & $\tau_{o}$ & $0.7(\mathrm{~s})$ \\
screen & $\tau_{c, o}$ & $0.7(\mathrm{~s})$ \\
& $\tau_{c}$ & $0.7(\mathrm{~s})$ \\
& $\tau_{f, c}$ & $1.4(\mathrm{~s})$ \\
\hline Mixing box & $V_{m b}$ & $0.0045\left(\mathrm{~m}^{3}\right)$ \\
\hline & $\alpha$ & 2.1 \\
DMC & $K_{c, o}$ & $60.55\left(\mathrm{~m}^{2} \mathrm{~s}\right)$ \\
& $K_{c, u}$ & $-0.45\left(\mathrm{~m}^{2} \mathrm{~s}\right)$ \\
& $K_{c, o, m e d}$ & $0.0059\left(\mathrm{~m}^{3} \mathrm{~s} / \mathrm{kg}\right)$ \\
& $K_{c, u, m e d}$ & $-0.00264\left(\mathrm{~m}^{3} \mathrm{~s} / \mathrm{kg}\right)$ \\
\hline \hline
\end{tabular}

Table 5 indicates the normalised FPE results for each equipment model that was identified.

Table 5: Model prediction-error identification method results.

\begin{tabular}{ll}
\hline Equipment model & Normalised FPE \\
\hline Double-deck screen with mixing box & 17.5 \\
DMC & -6.3 \\
\hline
\end{tabular}

\subsection{Steady-state model validation}

Meyer and Craig (2011) show how a dynamic DMC model can be reduced to a steady-state model. This steady-state model is similar to that of a partition curve used to determine the efficiency of a DMC. The principle used to generate such a curve is float and sink analysis where coal samples are collected and separated using different relative density fractions.

England et al. (2002) details the float and sink analysis used in this paper. Figure 4 illustrates how a sample is separated using containers with liquids of decreasing relative densities. The float of each container is recovered and used as feed for the next container. The analysis is performed at steady-state as each container must allow the sample to settle and separate.

By analysing the sinks at each density fraction, it is possible to generate a partition curve (England et al., 2002). Figure 5 shows the actual partition curve of the module one coarse DMC as determined from plant data.

The separation cutpoint $\left(\rho_{50}\right)$ can be determined as $1701 \mathrm{~kg} / \mathrm{m}^{3}$ - this is the specific density where a particle will have an equal chance of reporting to a float or sink. The écart probable moyen (EPM) is a parameter used to describe 


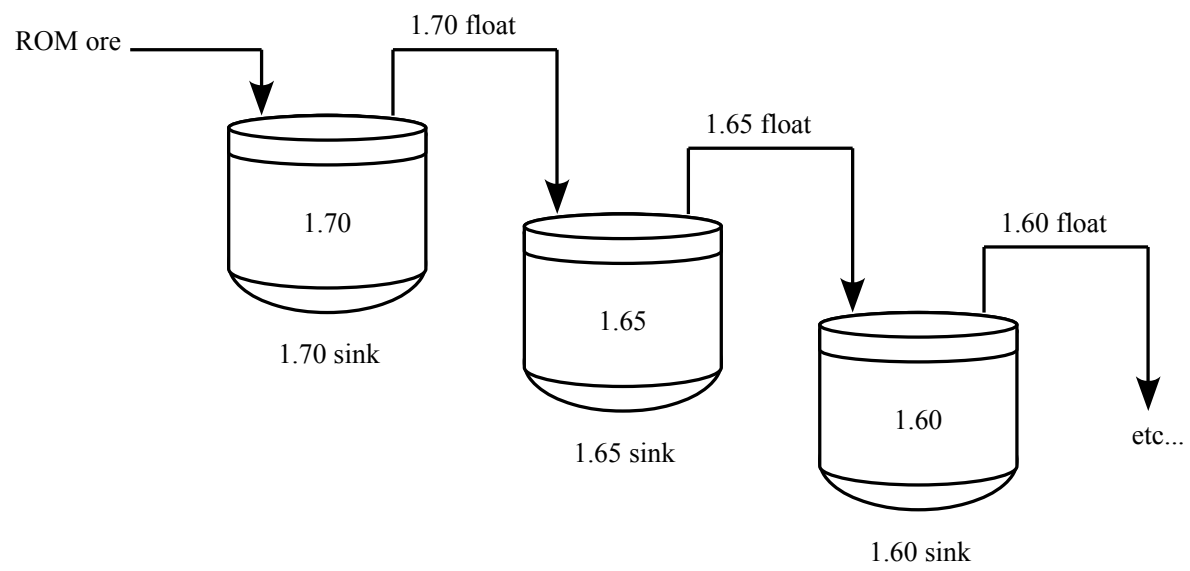

Figure 4: Sink and float analysis used to determine a partition curve.

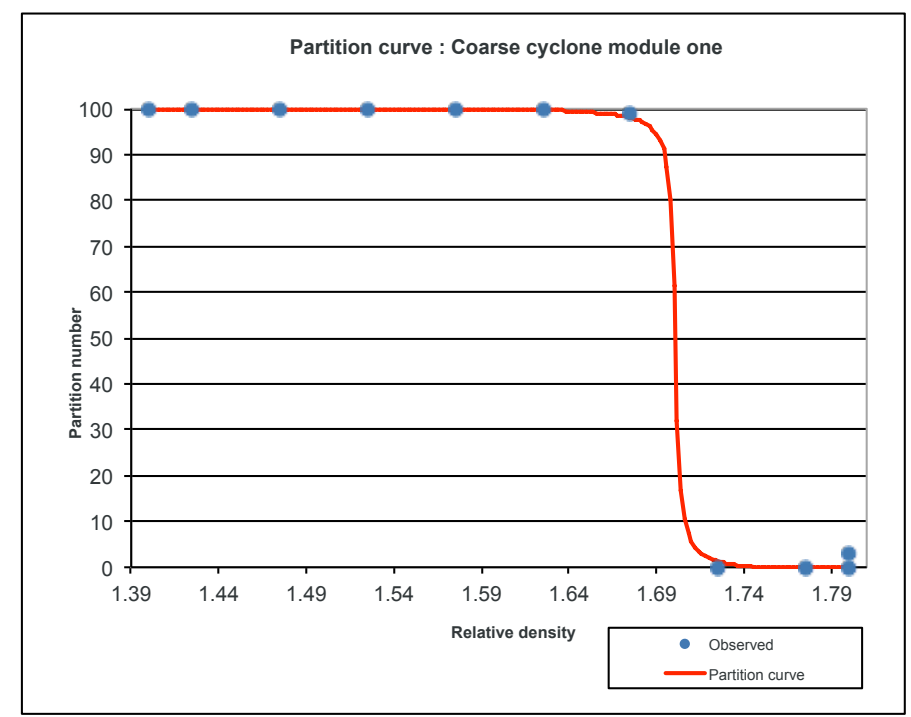

Figure 5: Module one coarse cyclone partition curve $(-25+6 \mathrm{~mm}$ coal). 
the sharpness of the curve. This separation efficiency is calculated as follows:

$$
\mathrm{EPM}=\frac{\rho_{25}-\rho_{75}}{2},
$$

where $\rho_{25}$ is the relative density at $25 \%$ and $\rho_{75}$ is the relative density at $75 \%$ (England et al., 2002). The EPM is determined as 0.0020 based on the partition curve in Figure 5. This low EPM is possibly due to the organic efficiency (ratio between actual yield achieved and theoretical yield from washability data) being very high (100\%).

\section{Simulation results and discussion}

This section details the simulation results for both experiments and also provides the resulting time-based correlation and goodness of fit for each dynamic model. A comparison is made between the time-based correlations with varying first-order low pass filter cut-off frequencies having a bandwidth of $1 / T_{s}$. Similarly, the goodness of fit is compared for different low pass filter cut-off frequencies. The correlation coefficient is calculated in time, and therefore it is possible to have close to $100 \%$ correlation but with a large constant error (offset) in the predicted values. The time period $\left(T_{s}\right)$ for the cut-off frequency is initially made to be $50 \mathrm{~s}$. It is then increased to $100 \mathrm{~s}$ and finally to 200s. Only the simulation graph of the DMC overflow coal product output is given as this output will typically be a controlled variable.

This section also shows the simulation output and model validation of the steady-state partition curve. The $\rho_{50}$ and EPM for the actual cyclone efficiency is compared to that of the simulated results at the end of this section.

\subsection{Experiment one}

This subsection details the results for experiment one where the medium density was maintained constant and the input feed was stepped up. The input data for this experiment are shown in Figure 6. The data used in experiment one consist of 6600 samples (taken every second) obtained from real DMS plant measurements. The following figures display the simulation results using a 200s time period for the low pass filter that was used to filter the plant measurements.

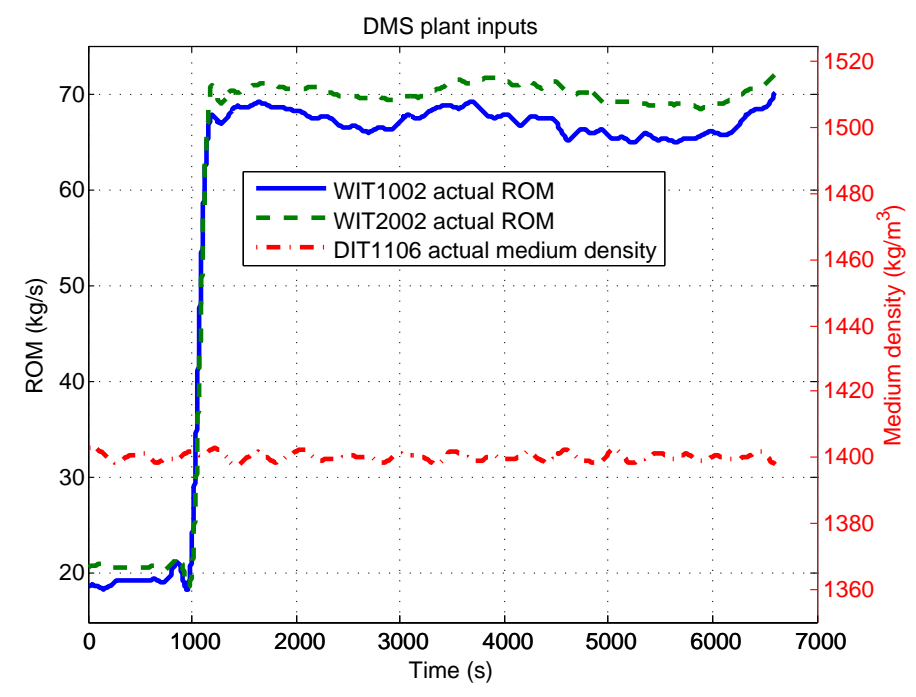

Figure 6: Plant input data for simulation $\left(T_{s}=200 \mathrm{~s}\right)$.

The primary screen with mixing box model was simulated where the combined coarse size and undersize feed rates (C01) are determined. The mixing box total mass rate $(\mathrm{CO2})$ and pressure feed to the cyclone were also determined. Figures 7 and 8 illustrate the comparison between the primary screen and mixing box measurement points and the outputs predicted by the model. Figure 9 illustrates the calculated mixing box total mass output $(\mathrm{CO2})$. Since no measurement is available for the total mass feed to the cyclone, the cyclone pressure is the best means of determining the model fit. 


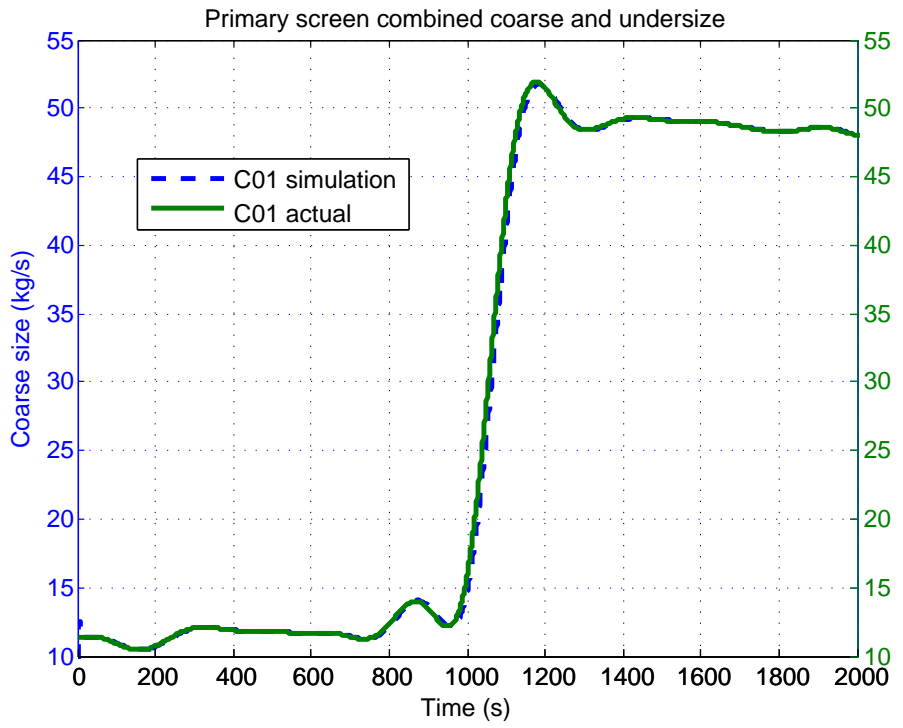

Figure 7: Primary screen coarse size and undersize simulation $\left(T_{s}=200 \mathrm{~s}\right)$.

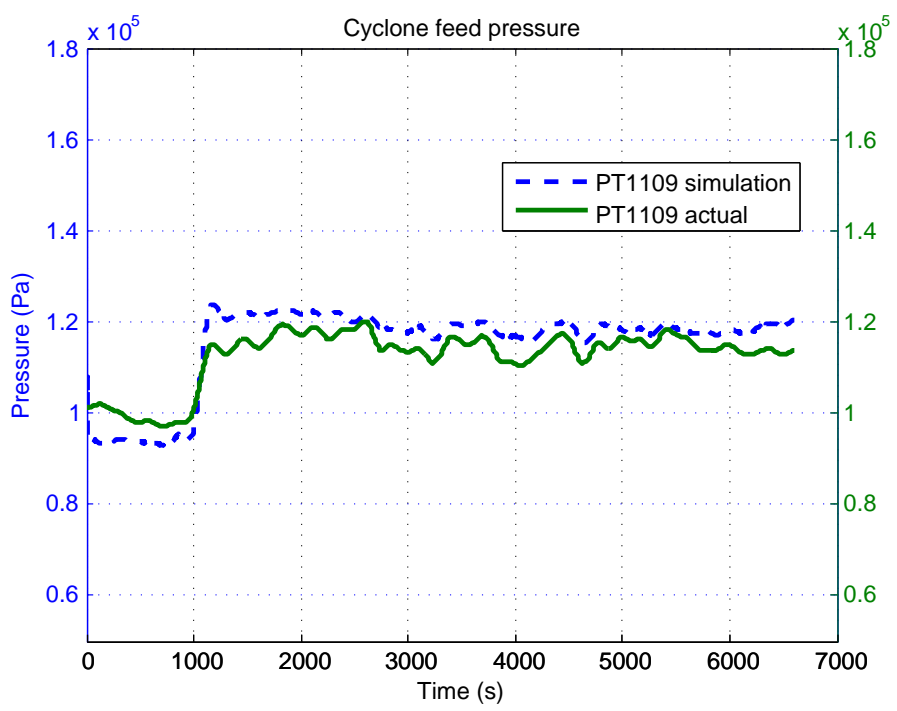

Figure 8: Mixing box pressure feed to cyclone simulation $\left(T_{s}=200 \mathrm{~s}\right)$. 


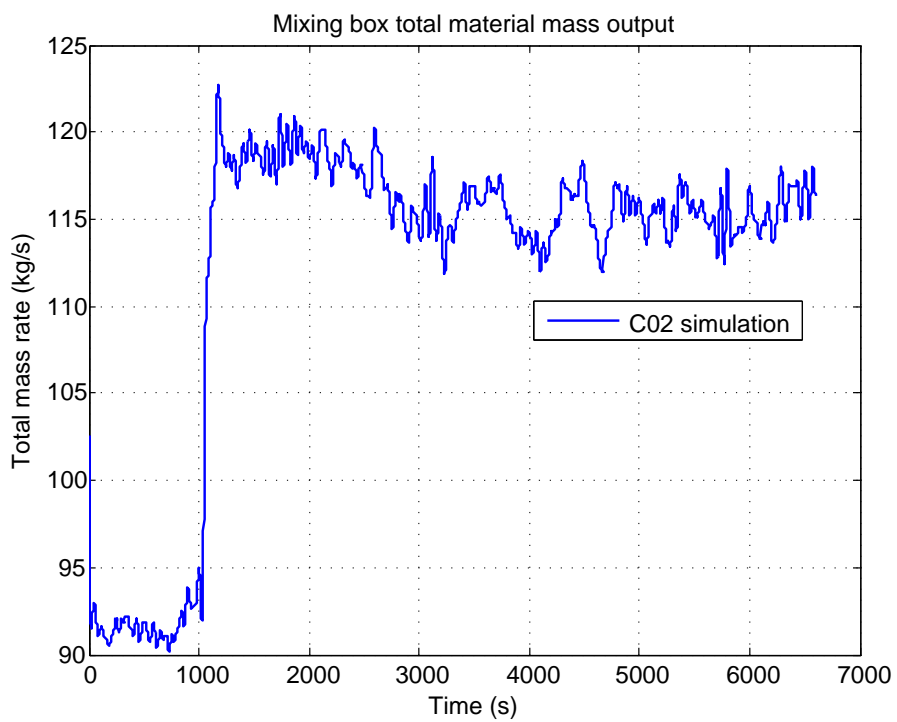

Figure 9: Mixing box total material mass rate simulation $\left(T_{s}=200 \mathrm{~s}\right)$.

Figure 10 illustrates the combined overflow and underflow medium simulation versus the actual RD measurement taken before mixing. The combined overflow and underflow medium simulation is calculated such that it can be used as an equivalent to the measured medium density plant data. Figures 11 and 12 show the simulation results of the DMC when compared to the calculated values using a time period of 50s. The output of the DMC will primarily be used for control purposes as this is the final product produced by the DMS plant which determines the yield and quality of the coal product.

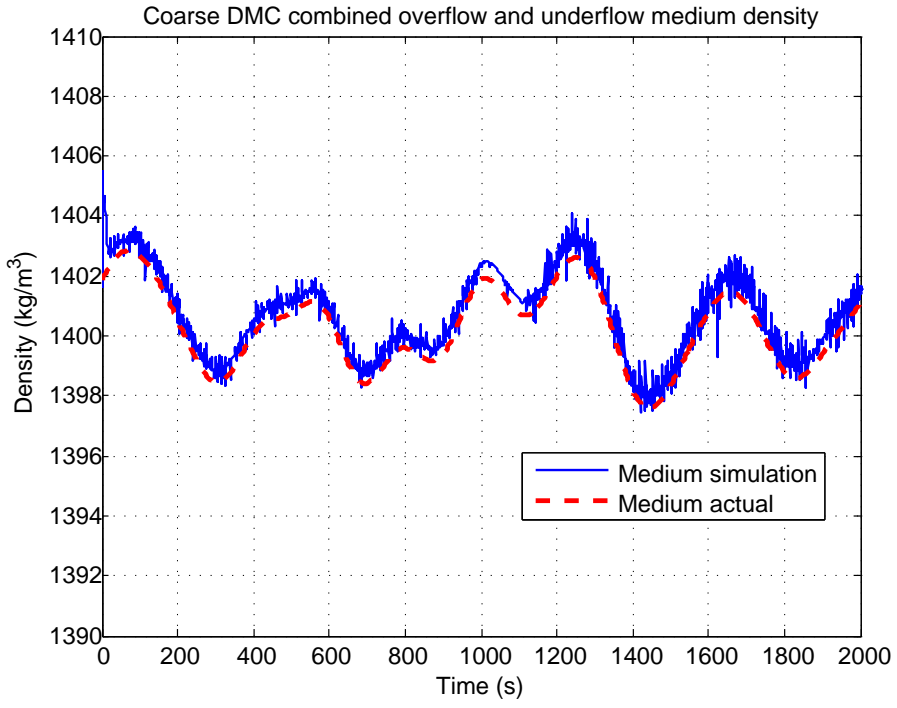

Figure 10: DMC combined overflow and underflow medium simulation $\left(T_{s}=200 \mathrm{~s}\right)$. 


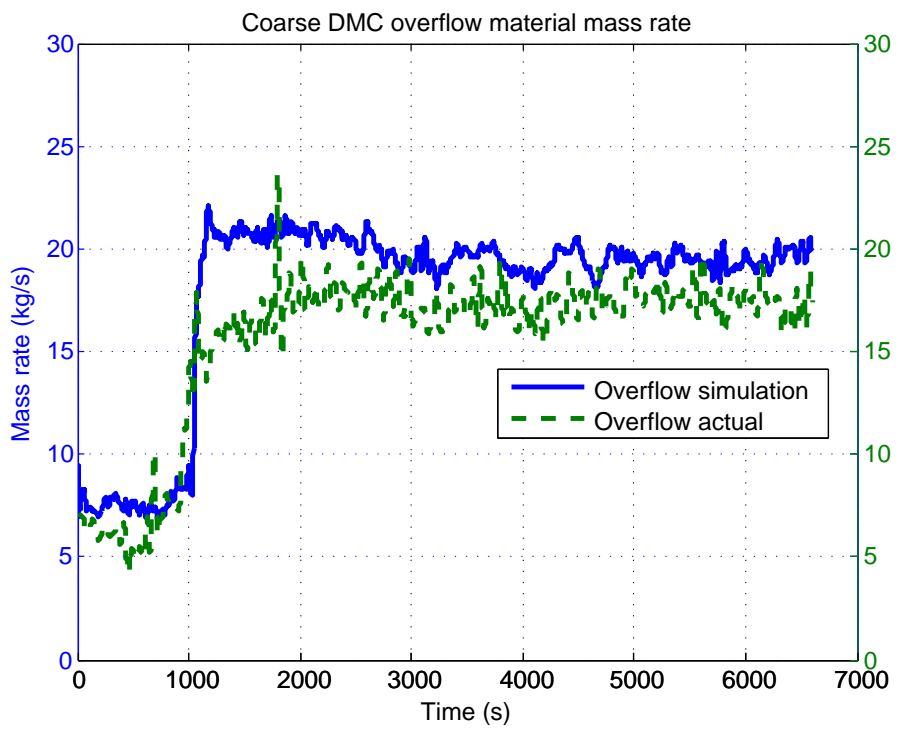

Figure 11: DMC overflow coal product simulation $\left(T_{s}=50 \mathrm{~s}\right)$.

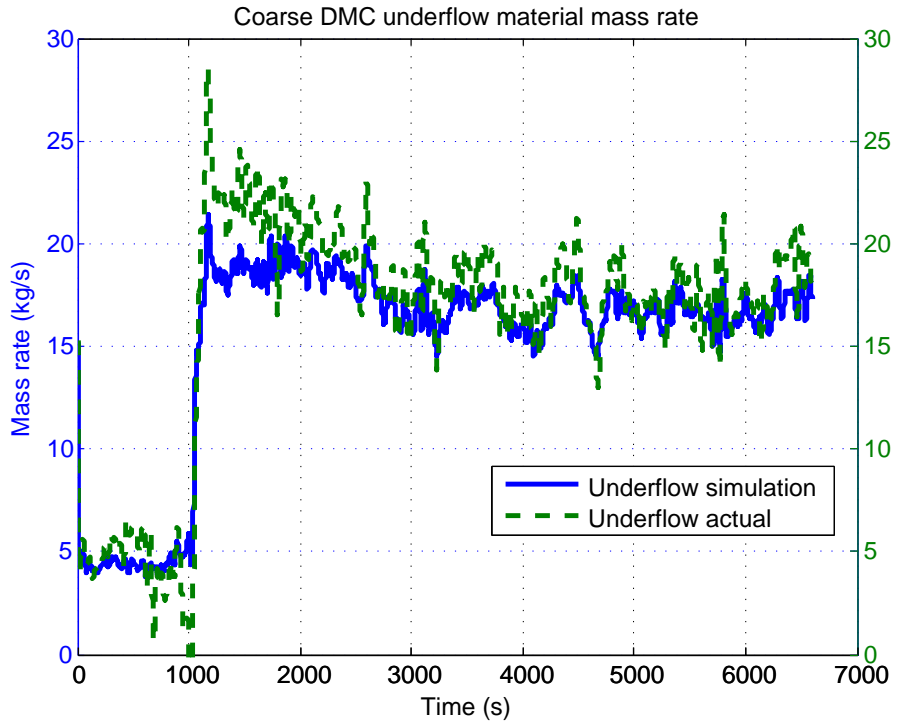

Figure 12: DMC underflow discard simulation $\left(T_{s}=50 \mathrm{~s}\right)$. 
Figure 13 illustrates the DMC simulation model output where the input data have been filtered using a low pass filter with a cut-off time period of 100s.

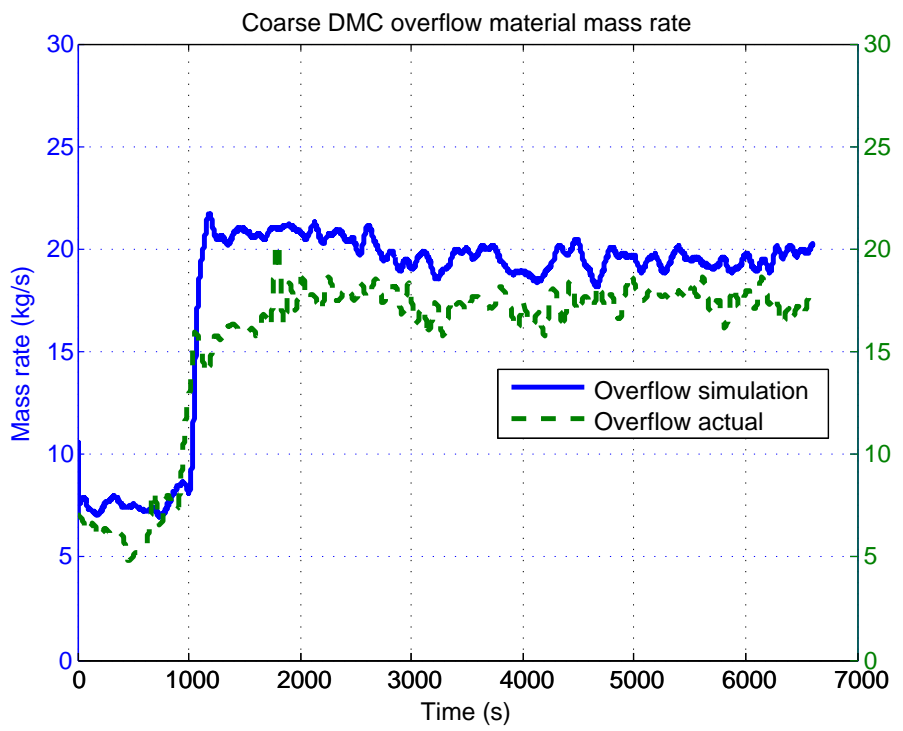

Figure 13: DMC overflow coal product simulation $\left(T_{s}=100 \mathrm{~s}\right)$.

Figure 14 illustrates the DMC simulation model output where the input data have been filtered using a low pass filter with a cut-off time period of 200s.

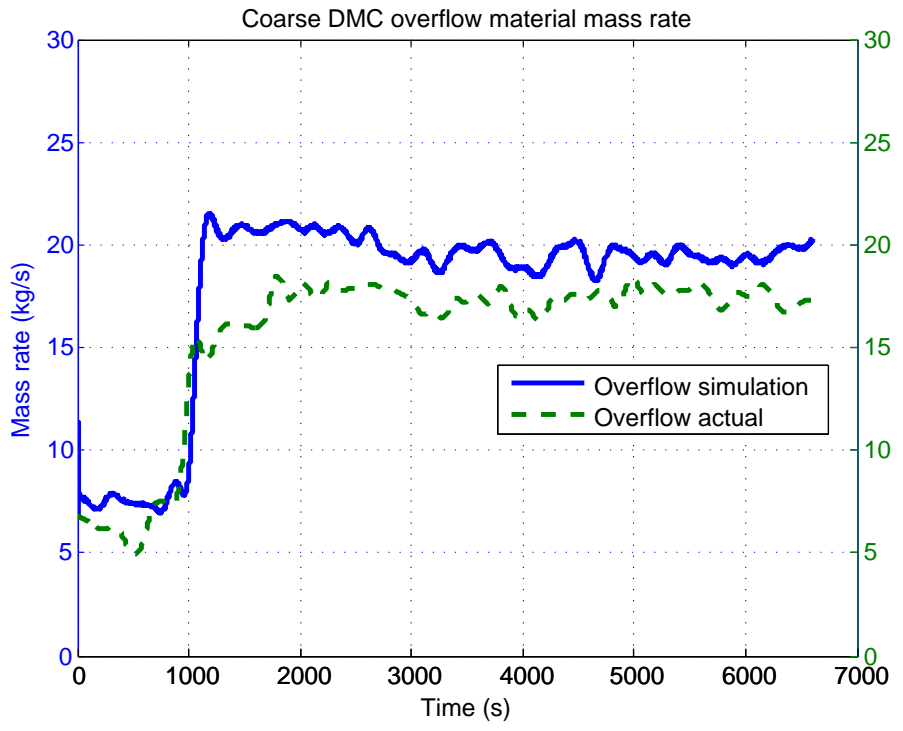

Figure 14: DMC overflow coal product simulation $\left(T_{s}=200 \mathrm{~s}\right)$. 
Table 6 shows the model goodness of fit (calculated using equation 6) for the different equipment models. A model goodness of fit of $100 \%$ represents a perfect fit. These results are given for each low pass filter cut off time period of 50 s, 100 s and 200s.

Table 6: Simulation fit results summary for feed rate step change.

\begin{tabular}{lllll}
\hline \multirow{2}{*}{ Equipment model } & \multicolumn{3}{c}{ Fit \% (Different $\left.T_{s}\right)$} \\
& & $50 \mathrm{~s}$ & $100 \mathrm{~s}$ & $200 \mathrm{~s}$ \\
\hline \hline $\begin{array}{l}\text { Double-deck } \\
\text { screen and } \\
\text { mixing box }\end{array}$ & $\begin{array}{l}\text { Coarse size } \\
\text { and undersize }\end{array}$ & 96.2 & 97.1 & 97.6 \\
\cline { 2 - 5 } DMC & $\begin{array}{l}\text { Cyclone feed } \\
\text { pressure }\end{array}$ & 25.1 & 24.7 & 24.8 \\
\hline & $\begin{array}{l}\text { Overflow coal } \\
\text { product }\end{array}$ & 31.4 & 32.2 & 32.8 \\
& $\begin{array}{l}\text { Underflow } \\
\text { discard }\end{array}$ & 66.6 & 68.0 & 68.8 \\
& $\begin{array}{l}\text { Overflow and } \\
\text { underflow } \\
\text { medium } \\
\text { density }\end{array}$ & 62.0 & 58.2 & 52.7 \\
\hline \hline
\end{tabular}

Table 7 shows the model correlation percentages for the different equipment simulation results. These results are given for each low pass filter cut-off time period of 50s, 100s and 200s.

\begin{tabular}{lllll}
\multicolumn{5}{c}{ Table 7: Simulation correlation results summary for feed rate step change. } \\
\hline \multicolumn{5}{c}{$\begin{array}{c}\text { Correlation \% } \\
\text { (Different } T_{s} \text { ) }\end{array}$} \\
\hline \hline & 50s & 100s & 200s \\
\hline $\begin{array}{l}\text { Double-deck } \\
\text { screen and } \\
\text { mixing box }\end{array}$ & $\begin{array}{l}\text { Coarse size } \\
\text { and undersize }\end{array}$ & 99.9 & 100.0 & 100.0 \\
\cline { 2 - 5 } & $\begin{array}{l}\text { Cyclone feed } \\
\text { pressure }\end{array}$ & 94.3 & 96.0 & 96.5 \\
\hline DMC & $\begin{array}{l}\text { Overflow coal } \\
\text { product }\end{array}$ & 93.8 & 94.9 & 95.6 \\
& $\begin{array}{l}\text { Underflow } \\
\text { discard }\end{array}$ & 97.2 & 97.7 & 98.0 \\
\hline & $\begin{array}{l}\text { Overflow and } \\
\text { underflow } \\
\text { medium } \\
\text { density }\end{array}$ & 97.7 & 97.1 & 96.4 \\
\hline
\end{tabular}

\subsection{Experiment two}

This subsection details the results for experiment two where the input feed was maintained constant and the medium density was stepped up. The input data for this experiment is shown in Figure 15. All the data used in experiment two consist of 6600 samples (taken every second) obtained from real DMS plant measurements. The following figures display the simulation results using a 200s time period for the low pass filter. 


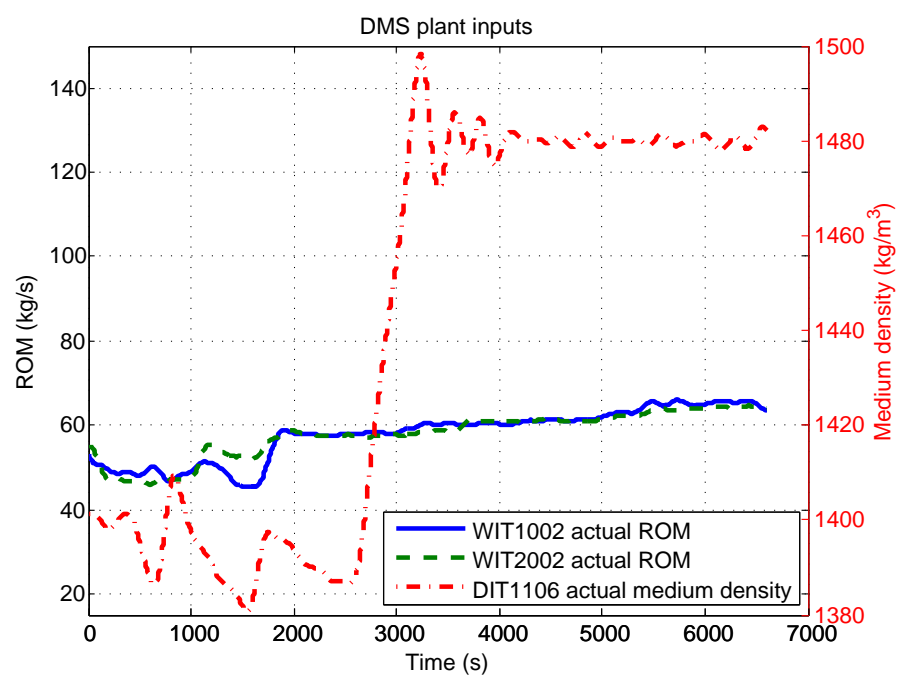

Figure 15: Plant input data for simulation $\left(T_{s}=200 \mathrm{~s}\right)$.

The primary screen with mixing box model was simulated where the combined coarse size and undersize feed rates $(C 01)$ are determined. The mixing box total mass rate $(C 02)$ and pressure feed to the cyclone were also determined. Figures 16 and 17 illustrate the comparison between the primary screen and mixing box measurement points and the predicted model outputs. Figure 16 only shows the results over the first 2000 s due to the high correlation between the actual and simulated output. Figure 18 illustrates the calculated mixing box total mass output (C02). Similar to experiment one, since no measurement is available for the total mass feed to the cyclone, the cyclone pressure is the best means of determining the model fit.

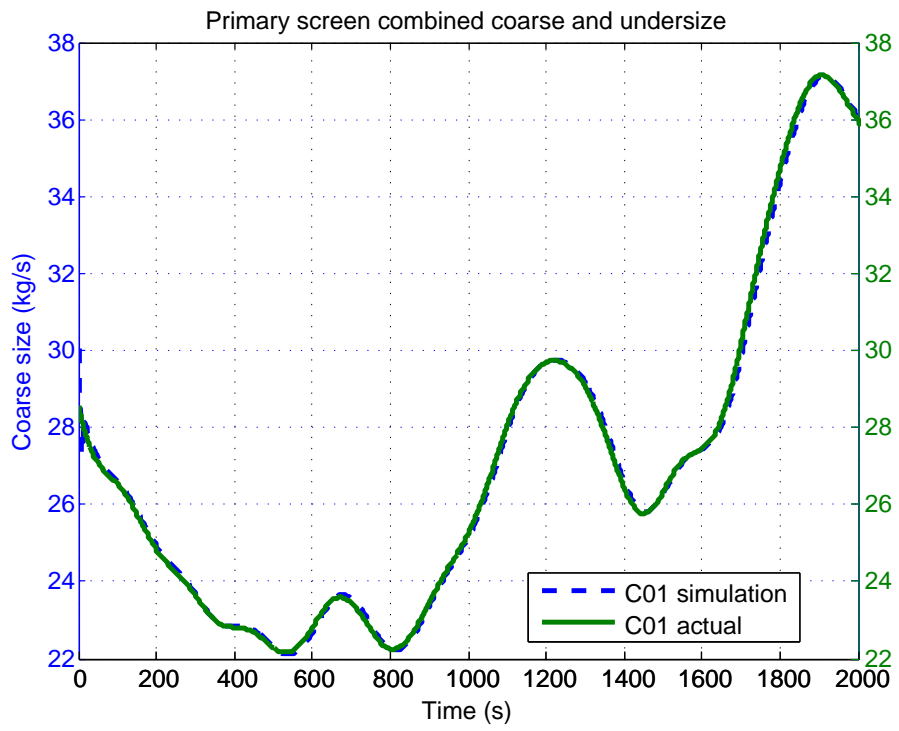

Figure 16: Primary screen coarse size and undersize simulation $\left(T_{s}=200 \mathrm{~s}\right)$. 


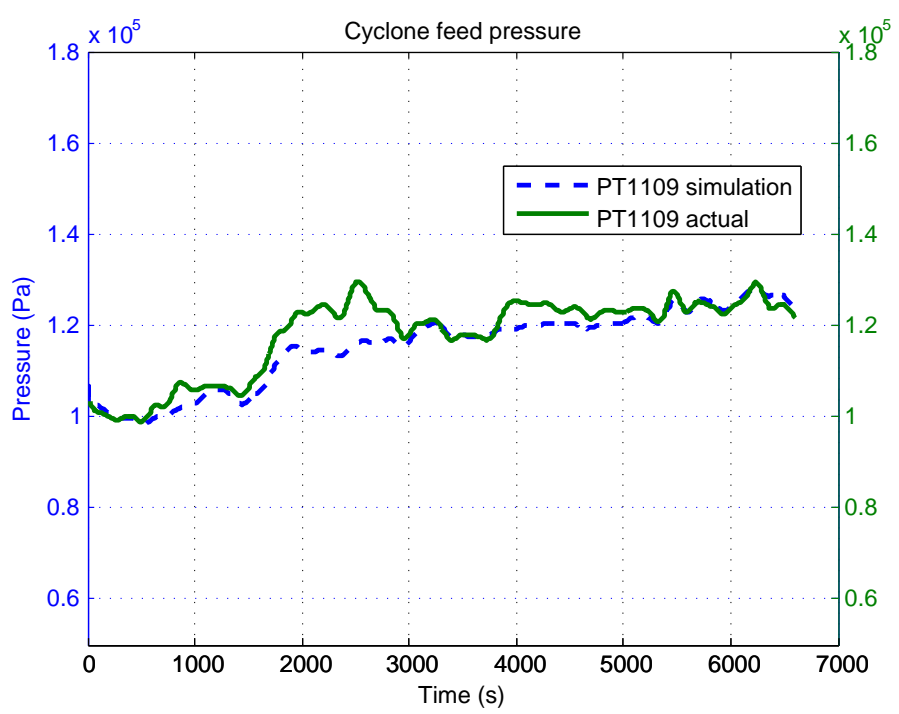

Figure 17: Mixing box pressure feed to cyclone simulation $\left(T_{s}=200 \mathrm{~s}\right)$.

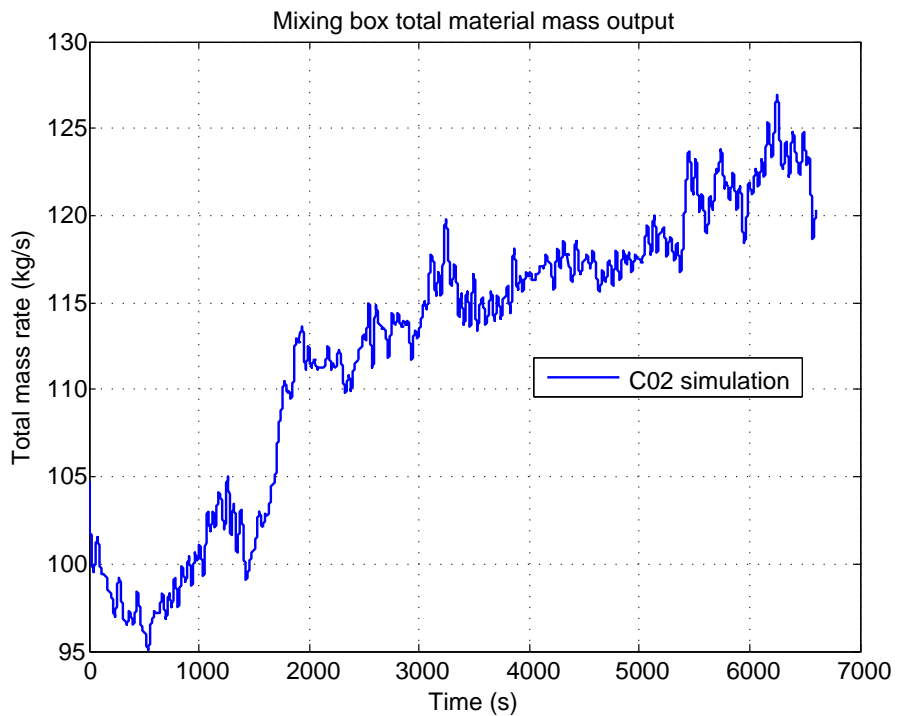

Figure 18: Mixing box total material mass rate simulation $\left(T_{s}=200 \mathrm{~s}\right)$. 
Figure 19 illustrates the combined overflow and underflow medium simulation versus the actual RD measurement taken before mixing. The combined overflow and underflow medium simulation is calculated such that it can be used as an equivalent to the measured medium density plant data. Figures 20 and 21 show the simulation results of the DMC when compared to the calculated values using a time period of 50s. The output of the DMC will primarily be used for control purposes as this is the final product produced by the DMS plant which determines the yield and quality of the coal product.

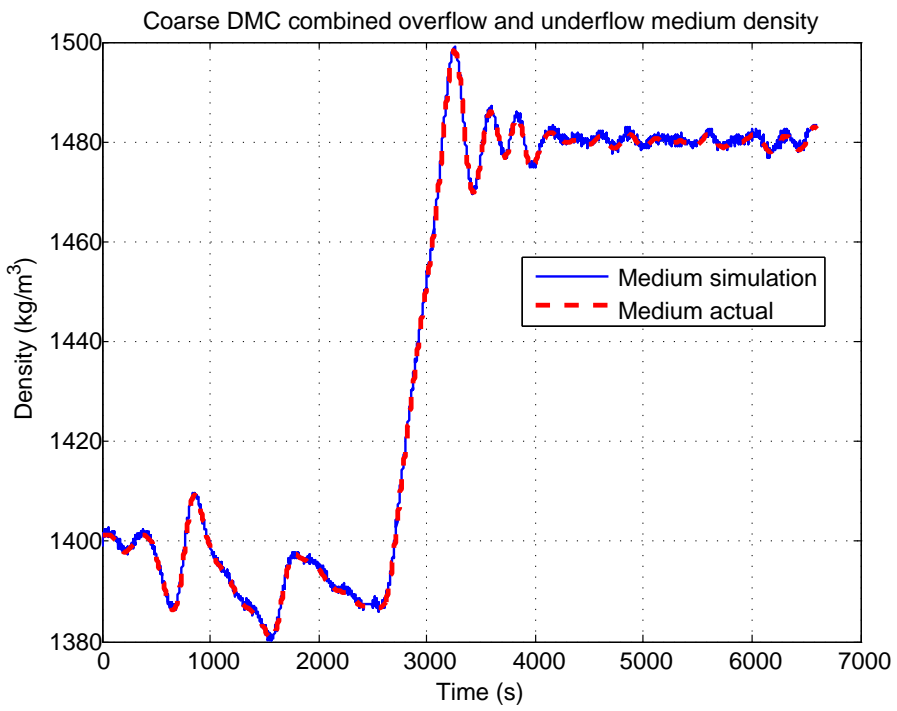

Figure 19: DMC combined overflow and underflow medium simulation $\left(T_{s}=200 \mathrm{~s}\right)$.

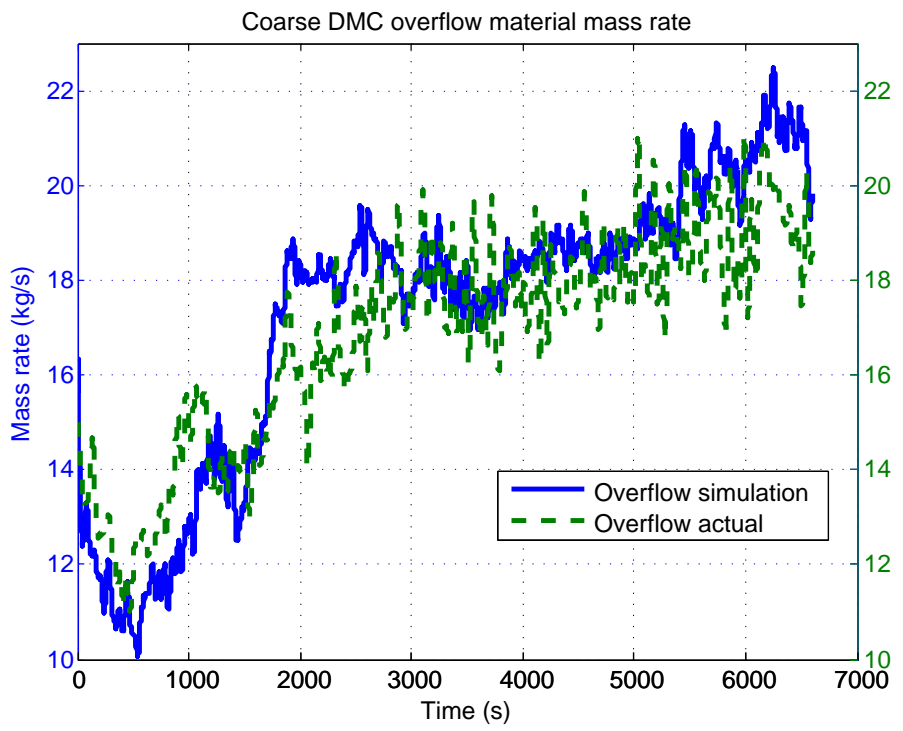

Figure 20: DMC overflow coal product simulation $\left(T_{s}=50 \mathrm{~s}\right)$. 


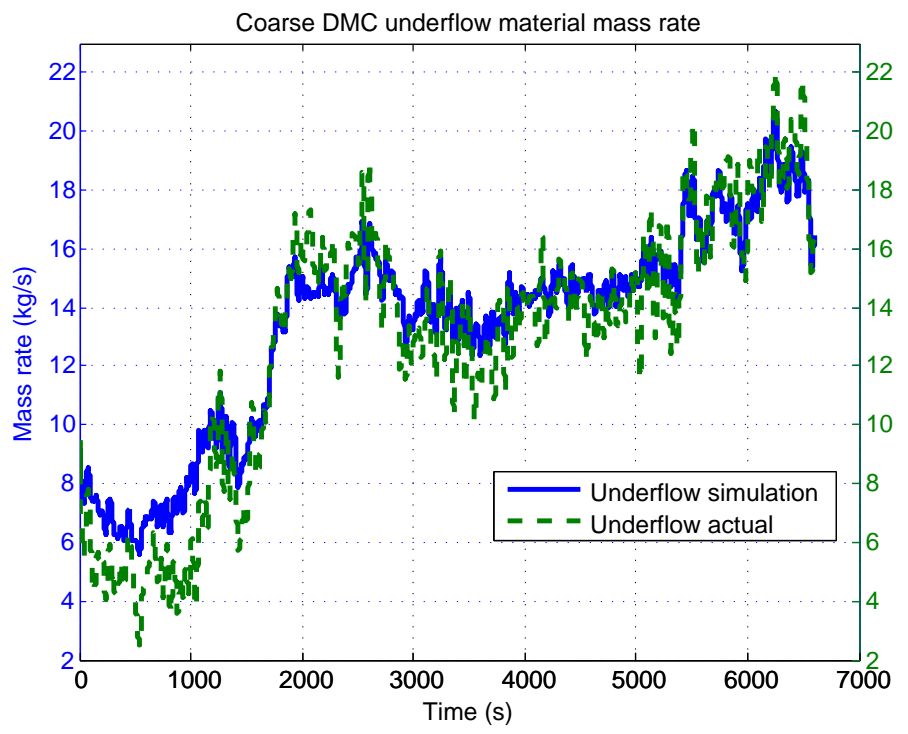

Figure 21: DMC underflow discard simulation $\left(T_{s}=50 \mathrm{~s}\right)$.

Figures 22 and 23 illustrate the DMC simulation model output where the input data have been filtered using low pass filters with cut-off time periods of 100s and 200s respectively.

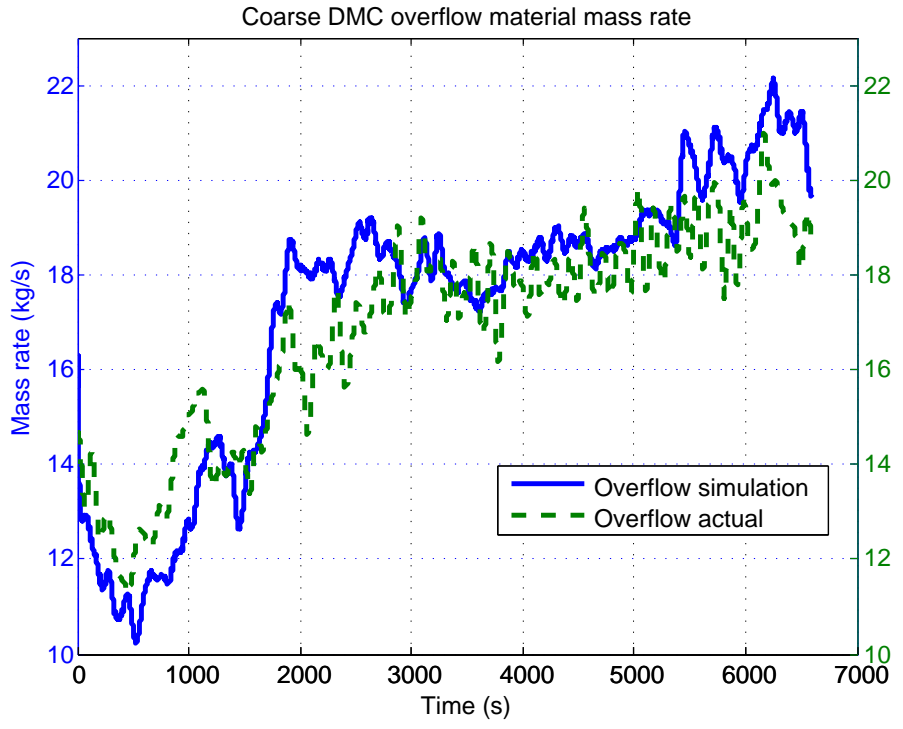

Figure 22: DMC overflow coal product simulation $\left(T_{s}=100 \mathrm{~s}\right)$. 


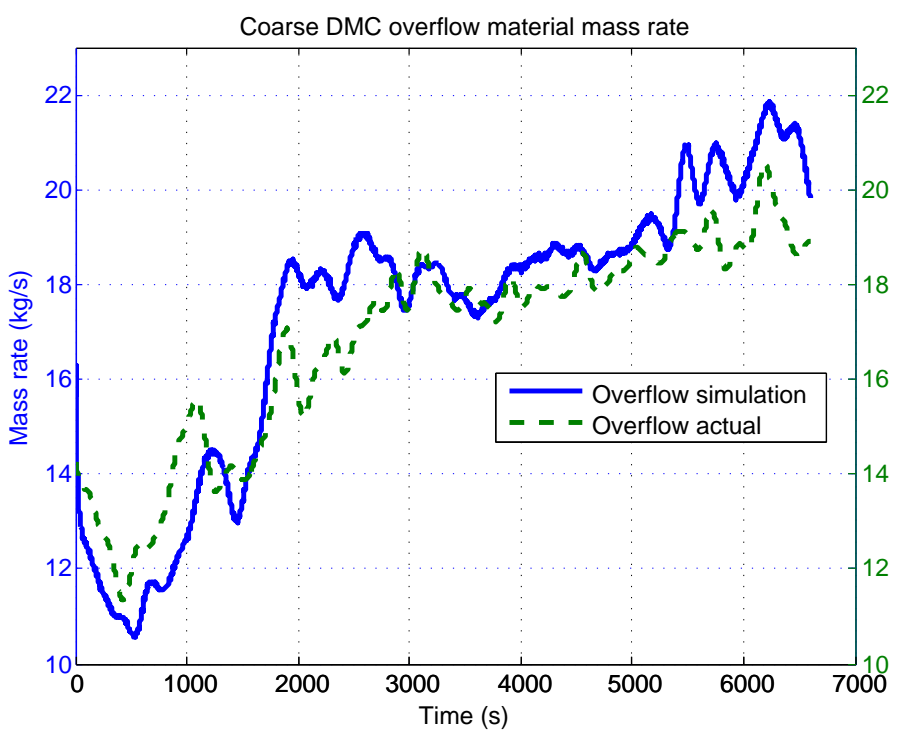

Figure 23: DMC overflow coal product simulation $\left(T_{s}=200 \mathrm{~s}\right)$.

Table 8 shows the model goodness of fit (calculated using equation 6) for the different equipment models. A model goodness of fit of $100 \%$ represents a perfect fit. These results are given for each low pass filter cut-off time period of 50s, 100s and 200s.

Table 8: Simulation fit results summary for density step change.

\begin{tabular}{lllll}
\hline \multirow{2}{*}{ Equipment model } & \multicolumn{4}{c}{ Fit \% (Different $T_{s}$ ) } \\
& $50 \mathrm{~s}$ & $100 \mathrm{~s}$ & $200 \mathrm{~s}$ \\
\hline \hline $\begin{array}{l}\text { Double-deck } \\
\text { screen and } \\
\text { mixing box }\end{array}$ & $\begin{array}{l}\text { Coarse size } \\
\text { and undersize }\end{array}$ & 97.2 & 98.0 & 98.5 \\
\cline { 2 - 5 } & $\begin{array}{l}\text { Cyclone feed } \\
\text { pressure }\end{array}$ & 49.0 & 50.5 & 50.9 \\
\hline \multirow{5}{*}{ DMC } & $\begin{array}{l}\text { Overflow coal } \\
\text { product }\end{array}$ & 38.6 & 41.7 & 44.0 \\
& $\begin{array}{l}\text { Underflow } \\
\text { discard }\end{array}$ & 69.8 & 71.9 & 73.5 \\
\hline & $\begin{array}{l}\text { Overflow and } \\
\text { underflow } \\
\text { medium } \\
\text { density }\end{array}$ & 98.6 & 98.7 & 98.7 \\
\hline \hline
\end{tabular}


Table 9 shows the model correlation percentages for the different equipment simulation results. These results are given for each low pass filter cut-off time period of 50s, 100s and 200s.

\begin{tabular}{|c|c|c|c|c|}
\hline \multirow{2}{*}{\multicolumn{2}{|c|}{ Equipment model }} & \multicolumn{3}{|c|}{$\begin{array}{l}\text { Correlation \% } \\
\left(\text { Different } T_{s}\right)\end{array}$} \\
\hline & & $50 \mathrm{~s}$ & $100 \mathrm{~s}$ & $200 \mathrm{~s}$ \\
\hline \multirow{2}{*}{$\begin{array}{l}\text { Double-deck } \\
\text { screen and } \\
\text { mixing box }\end{array}$} & $\begin{array}{l}\text { Coarse size } \\
\text { and undersize }\end{array}$ & 100.0 & 100.0 & 100.0 \\
\hline & $\begin{array}{l}\text { Cyclone feed } \\
\text { pressure }\end{array}$ & 91.0 & 92.2 & 92.3 \\
\hline \multirow{3}{*}{ DMC } & $\begin{array}{l}\text { Overflow coal } \\
\text { product }\end{array}$ & 90.9 & 93.2 & 95.0 \\
\hline & $\begin{array}{l}\text { Underflow } \\
\text { discard }\end{array}$ & 97.8 & 98.3 & 98.9 \\
\hline & $\begin{array}{l}\text { Overflow and } \\
\text { underflow } \\
\text { medium } \\
\text { density }\end{array}$ & 100.0 & 100.0 & 100.0 \\
\hline
\end{tabular}

\subsection{Steady-state partition curve}

This subsection details the simulated results of a steady-state model based on the dynamic model given in section 3. The procedure detailed in Meyer and Craig (2011) was used to simulate the partition curve. A model fit was performed using the partition curve from Napier-Munn (1991). This partition curve describes the partition factor $(\mathrm{P})$ as a function of particle density $(\rho)$ with the separation cutpoint $\left(\rho_{50}\right)$ and EPM $\left(E_{p}\right)$ as parameters,

$$
\mathrm{P}=\frac{1}{1+e^{\frac{1.099\left(\rho_{50}-\rho\right)}{E_{p}}}}
$$

The simulated steady-state partition curve is similar to that described in section 3 . The predicted mass distributions to float and sink products at different particle densities in the feed $(\rho)$ are obtained by simulating the partition factor at different medium densities. By starting with a finite amount of mass in the feed and simulating the separation at steady-state at a high density, the resulting mass in the float can be used as the feed for the next steady-state simulation. With decreasing medium density iterations, the resulting partition factors can be obtained. The simulation should start slightly higher than the expected $\rho_{50}$ to generate the efficiency portion of the curve. By fitting equation 8 to the simulated observations the partition curve in Figure 24 was generated. The simulated partition curve is based on the dynamic models with parameters from Table 4 which were determined from both experiment one and two data. 


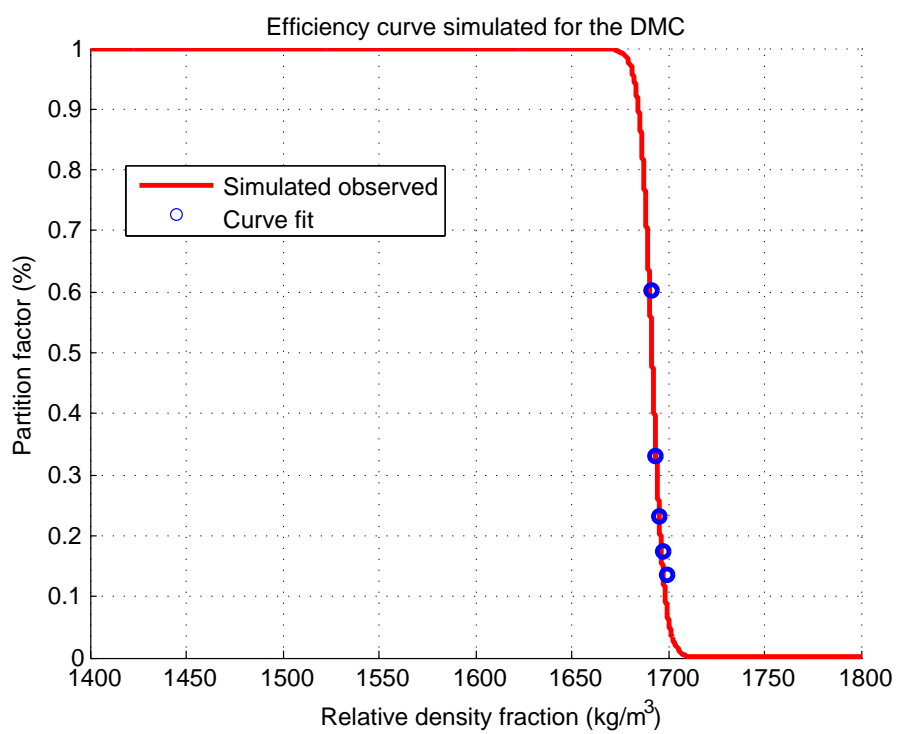

Figure 24: Simulated efficiency curve for the DMC using the steady-state model reduced from a dynamic DMC model.

Using the results from the curve fit the parameters obtained are a $\rho_{50}$ of $1692 \mathrm{~kg} / \mathrm{m}^{3}$ and an EPM of $0.0035 \mathrm{~kg} / \mathrm{m}^{3}$.

Table 10 shows a summary of the efficiency parameters for the simulated partition curve and the actual plant operation cyclone efficiency curve. This simulation indicates that a dynamic DMC model can be reduced to a realistic steady-state model from which a partition curve can be generated. The actual partition curve in Figure 5 was determined at a different time period to when the simulated partition curve was generated. This could be a possible reason as to why the EPM differs slightly between the actual and simulated partition curve.

Table 10: Partition curve efficiency results summary.

\begin{tabular}{llll}
\hline $\begin{array}{l}\text { Efficiency } \\
\text { parameter }\end{array}$ & $\begin{array}{l}\text { Simulated } \\
\text { steady-state } \\
\text { model results }\end{array}$ & $\begin{array}{l}\text { Actual plant } \\
\text { results }\end{array}$ & \\
\hline$\rho_{50}\left(\mathrm{~kg} / \mathrm{m}^{3}\right)$ & 1692 & 1701 & \\
\hline$E_{p}\left(\mathrm{~kg} / \mathrm{m}^{3}\right)$ & 0.0035 & 0.0020 & \\
\hline
\end{tabular}

\section{Conclusion}

This paper shows how the dynamic mathematical models developed by Meyer and Craig (2010) can be applied to a coarse DMC circuit. The models were identified using two sets of experimental data. The first experiment includes a step response in ore feed rate while maintaining the medium RD constant. The second experiment maintains the ore feed rate while introducing a step response in the medium RD. The model parameters were estimated from both sets of experimental values to obtain both sets of simulations. This means that the models will cater for different operating conditions such as changes in ore feed rate or changes in medium RD. This paper also shows how the dynamic model of the DMC can be reduced to a steady-state model, similar to the work by Meyer and Craig (2011), which is then simulated to produce a partition curve. This partition curve is compared to the actual plant cyclone partition curve.

For the ore feed rate step response (experiment one), the model fit performed well with the coarse size and undersize feed rate. The cyclone feed pressure fit was the least accurate with the overflow coal product feed rate being the second least accurate. The underflow discard mass flow rate and overflow and underflow medium density fit performed relatively well. The lower fit for the cyclone feed pressure could be a result of the pressure sensor being inaccurate or the volumetric flow rate to the cyclone changing (The volumetric feed rate is not measured and 
assumed constant). The time-based correlation between the model output and measured output is very high for all measurements $(>90 \%)$.

In the medium RD step response (experiment two), the results are generally better than experiment one. The reason for the feed fit (experiment one) not being as good as the medium (experiment two) is that the feed input is not sufficiently rich to excite all the dynamics in the circuit. The medium has more variation in the input and hence the better fit. If additional up and down steps were introduced in the feed (experiment one) there might be an improvement in model fit.

The lowest accuracy model fit is in the overflow coal product feed rate while the cyclone feed pressure is the second lowest accuracy model fit. The model fit performed very well with the coarse size and undersize feed rates and the overflow and underflow medium density measurements. Similar to experiment one, the lower fit for cyclone feed pressure could be a result of inaccurate pressure measurement or varying volumetric flow rates, which are not measured, indicating that there is a general problem with the cyclone measurement. This measurement problem is probably due to the feed volumetric flow rate as the cyclone pressure is dependant on this. Similar to experiment one, the time-based correlation between the model output and measured output is very high (also $>90 \%$ ).

In both experiments, the model fit for the overflow coal product is low. This consistency implies that there could be a problem with the measured coarse coal product. In fact, the final products for this specific plant are combined and then processed through a screen which separates the coarse product from the fine product. The mass flow rate for each product is only measured on the final product belts after this separation screen. This screening could be the cause for the low model fit in the final product.

For both experiments, the data was filtered with low-pass filters with different cut-off frequencies to see the effect on model fit with reduced noise in the measurement data. The model fit and correlation is shown to improve with increased filtering of data. In general, the model fitted the density step response (experiment two) better than the ore feed rate step response (experiment one). Metallurgically, this makes sense as the DMS operation yield should be impacted primarily by medium RD setpoint changes, rather than changes in ore feed rates. The throughput input change in the first experiment appears to excite the process dynamics to a lesser extent than the medium density change in the second experiment. The fact that the throughput input signal could possibly be made better to excite the process dynamics could explain why the model derived from the second experiment provided a better fit to the plant data.

This paper also shows the results of the dynamic model reduction to a steady-state model for the simulation of a partition curve. It is shown that the separation cutpoint $\left(\rho_{50}\right)$ and EPM is similar to that of the actual plant DMC even though these data was not obtained during the same time as the data obtained for experiment one and two. It was however obtained during the same month of production. This might be the cause for the very slight deviation in results between the simulated and actual efficiency results.

The ultimate objective of this work is to develop a model suitable for process control, and to use such a controller to improve overall product throughput and quality. If these models are to be used in a MPC, the control objective will also need to be considered. Further work should be conducted to develop a MPC with a control objective to ensure overall production efficiency.

\section{Acknowledgements}

Our appreciation goes to Exxaro Resources for their support in providing the necessary production data from one of their coal preparation sites.

\section{References}

Bauer, M., Craig, I.K., 2008. Economic assessment of advanced process control - a survey and framework. Journal of Process Control 18 , 2-18. Camacho, E., Bordons, C., 2004. Model Predictive Control. Advanced Textbooks in Control and Signal Processing. 2 ed., Springer-Verlag London Limited, London.

England, T., Hand, P.E., Michael, D.C., Falcon, L.M., Yell, A.D., 2002. Coal Preparation in South Africa. 4 ed., Natal Witness Commercial Printers, Pietermaritzburg, South Africa.

Gupta, A., Yan, D., 2006. Mineral Processing Design and Operations: An Introduction. 1 ed., Elsevier, Amsterdam, The Netherlands.

He, Y.B., Laskowski, J.S., 1994. Effect of dense medium properties on the separation performance of a dense medium cyclone. Minerals Engineering 7, 209-221. 
Ljung, L., 1987. System Identification: Theory for the User. 1 ed., Prentice-Hall, Inc, Englewood Cliffs, NJ.

Ljung, L., 2005. System identification toolbox user's guide. 7 ed., The MathWorks, Inc, Natick, MA, USA.

Ljung, L., 2010. Perspectives on system identification. Annual Reviews in Control 34, 1-12.

Lyman, G.J., Askew, H., Wood, C.J., Davis, J.J., 1982. Dynamic modelling of dense medium cyclone washing circuits, in: Proceedings of the Mill Operations Conference, NW Queensland, Australia, AusIMM. pp. 369-381.

Lyman, G.J., Denney, B., Wood, C.J., Askew, H., Brenchley, R., 1983. Automatic control of product coal ash content using on-line coal ash gauge, in: Whitmore, R.L. (Ed.), Proceedings of the Second Australian Coal Preparation Conference, 1983, Rockhampton, Australia, Australian Coal Preparation Society. Australian Coal Preparation Society. pp. 291-309.

Meyer, E.J., 2010. The development of dynamic models for a dense medium separation circuit in coal beneficiation. Master's thesis. University of Pretoria.

Meyer, E.J., Craig, I.K., 2010. The development of dynamic models for a dense medium separation circuit in coal beneficiation. Minerals Engineering 23, 791-805.

Meyer, E.J., Craig, I.K., 2011. Development of a steady-state partition curve from a dense medium cyclone dynamic model in coal beneficiation, in: Proceedings of the 18th IFAC World Congress, Milano, Italy, IFAC. pp. 10523-10528. doi:10.3182/20110828-6-IT-1002.02846.

Mukherjee, A.K., Sripriya, R., Rao, P.V.T., Das, P., 2003. Effect of increase in feed inlet pressure on feed rate of dense medium cyclone. International Journal of Mineral Processing 69, 259-274.

Napier-Munn, T.J., 1991. Modelling and simulating dense medium separation processes - a progress report. Minerals Engineering 4, 329-346.

Rathaba, L.P., 2004. Model fitting for electric arc furnace refining. Master's thesis. University of Pretoria.

Stephanopoulos, G., 1984. Chemical process control: an introduction to theory and practice. 1 ed., Prentice-Hall, Inc., Englewood Cliffs, New Jersey. 